\title{
Sex and Age Differences of Normal $P$ Loops in the Frank Lead Vectorcardiogram
}

\author{
Mitsuhiro Yокота, M.D., Yoshitaka Ishibe, M.D., \\ Kazunobu Yamauchi, M.D., Hidehiko Tanimura, M.D., \\ Yoshihiko Watanabe, M.D., Iwao Sotobata, M.D., \\ and Shoji Yasui, M.D.
}

SUMmary

Noise-free and enlarged P loops of the Frank lead system were obtained from 164 normal Japanese males and 137 females (mean age: 34.4 and 33.2 years, respectively) with computer-averaging technique of 8 consecutive beats. Automated measurements concerning 17 parameters of the $\mathrm{P}$ loop ( $\mathrm{P}$ durations, magnitudes, and directions of 3 planar, spatial maximal, and mean polar $\mathbf{P}$ vector) were carried out. At the same time, sex and age differences were statistically analyzed.

\section{Sex differences}

Significant sex differences were found in 5 items in the first age group (20-29 years), 3 items in the second ( $30-39$ years), and 7 items in the third ( $40-49$ years).

II. Age differences

In males, the effect of aging was observed in 5 parameters out of 17 , in time durations extended and maximal vectors displaced posteriorly. In females, changes with advancing age were observed in 13 items out of 17 , thus leaving only 4-parameter, including frontal maximal $\mathrm{P}$ vectors and directions of mean polar $\mathrm{P}$ vectors as unaffected.

\section{Additional Indexing Words :}

Computer-averaging technique vectorcardiogram Sex difference

Normal P loop Frank-lead Age difference

$V^{n}$

ARIOUS studies have been reported on the normal values and ranges of the $\mathbf{P}$ loop in the Frank lead vectorcardiogram (VCG) of Japanese as well as European and American populations. ${ }^{2)-5}$. Despite the general agreement, however, that pertinent information on sex and age differences is essential for a proper VCG diagnosis, very few, if any, detailed reports ${ }^{1,4)}$ in this connection have been published.

From the First Department of Internal Medicine, Nagoya University School of Medicine, 65 Tsurumai-cho, Showa-ku, Nagoya 466, Japan.

Received for publication February 9, 1976. 
The purpose of this study is to establish a basis for diagnostic standards of $\mathbf{P}$ loop measurements in the Frank VGG for different age groups and sex.

\section{Subjects And Methods}

The material of the present study consisted of 164 normal males and 137 normal females, varying in age from 24 to 49 years (mean age: 34.3 and 33.2 years, respectively). Most of them were employees of various companies where health control was carefully practiced, and the rest was staff members of the Nagoya University Hospital. All satisfied the following requirements.

1) Maintaining health and free from cardiovascular and/or related diseases, past and present.

Table I. Age and Sex Distributions of Subjects

\begin{tabular}{c|cc}
\hline Age (yrs.) & \multicolumn{2}{c}{ Number of Cases } \\
& Male & Fernale \\
$20-29$ & 58 & 39 \\
$30-39$ & 50 & 54 \\
$40-49$ & 56 & 44 \\
\hline Total & 164 & 137
\end{tabular}

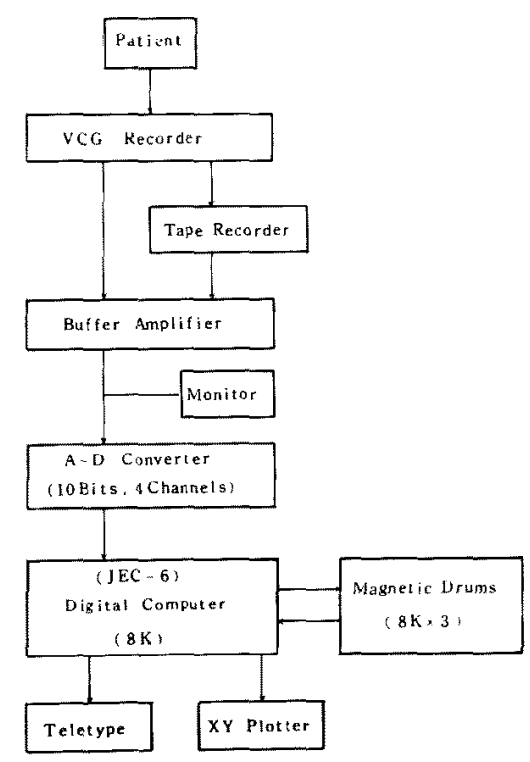

Fig. I Block diagram of the computer system. Details are described in the text.

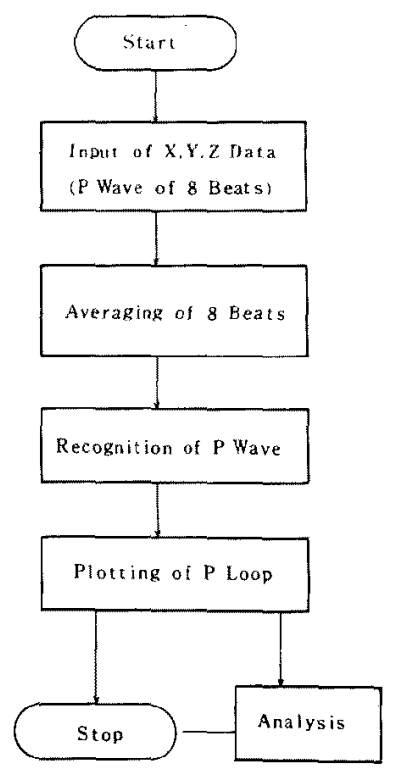

Fig. 2 Flow chart of the P loop analysis. Details are described in the text. 
2) Having a heart rate in the range of $60-90 / \mathrm{min}$, systolic blood pressure lower than $150 \mathrm{mmHg}$, diastolic blood pressure lower than $90 \mathrm{mmHg}$, and diagnosed as being free from other physiological disorders.

3) Showing no abnormalities in the P, QRS complex, and ST-T of the standard 12-lead electrocardiogram (ECG) and no arrhythmia.

Sex and age distributions of these subjects are given in Table I.

The Frank lead system was employed with the chest electrodes placed at the level of the fifth intercostal space of the subject in the supine position. The X, Y, and $\mathrm{Z}$ leads were amplified with a 3-channel electrocardiograph (Fukuda, RS$301 \mathrm{D}$ ) and fed into an A-D converter (10-bit, 4-channel) through a buffer amplifier (4-channel). The input signals were processed by the JEC-6 digital computer (core memory: $8 \mathrm{kw}$ ) with an auxiliary memory unit comprised of 3 magnetic drums $(8 \mathrm{kw} \times 3)$ before they were displayed on an $\mathrm{X}-\mathrm{Y}$ plotter and a teletype. A block diagram of this computer system ${ }^{11}$ layout is shown in Fig. 1.

Fig. 2 shows the flow chart of automated acquisition and display of the $P$ loop data. After applying $\mathrm{X}, \mathrm{Y}$, and $\mathrm{Z}$ calibration signals, A-D conversion was executed at a frequency of 500 times per second, with concurrent and successive measurements of potential differences between 2 consecutive points $12 \mathrm{msec}$ apart to search for the maximum value. The point where the amplitude is $75 \%$ of this maximum value was taken as the trigger for QRS wave recognition (Fig. 3). A $350 \mathrm{msec}$ interval preceding this trigger point was designated as the $\mathrm{P}$ wave zone and voltage summation of the zone was carried out over 8 bcats.

Determination of the onset and end of the $P$ wave was made with use of differential ECG of the scalar leads and spatial magnitude ECG, respectively.

In this study, the so-called man-machine system is employed, which is so designed that the points of recognition are indicated on the $\mathrm{X}, \mathrm{Y}$, and $\mathrm{Z}$ scalar ECGs drawn by an X-Y plotter (Fig. 4), and the operator can make visual confirmation as to whether the recognition points are satisfactory. When these are not adequate,

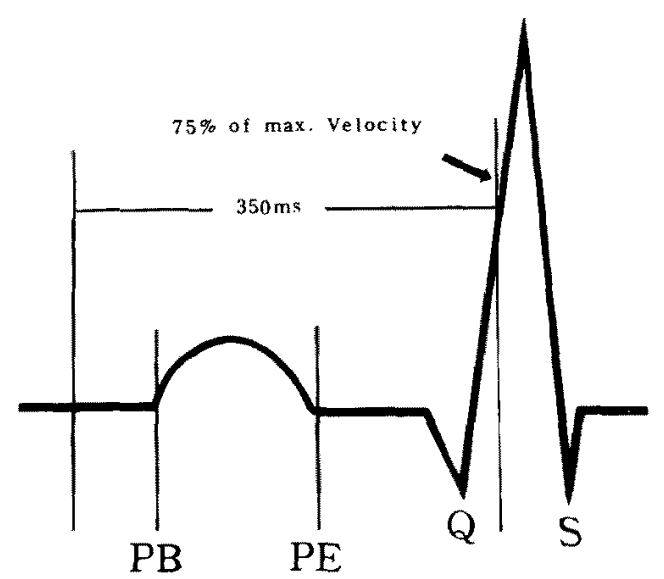

Fig. 3. Schematic representation of the decision of the $P$ wave area. The marked ( ) point means the amplitude of the $75 \%$ maximum value of the potential differences.

$\mathrm{PB}$ : the beginning of the $\mathrm{P}$ wave, $\mathrm{PE}$ : the end of the $\mathrm{P}$ wave. 
(

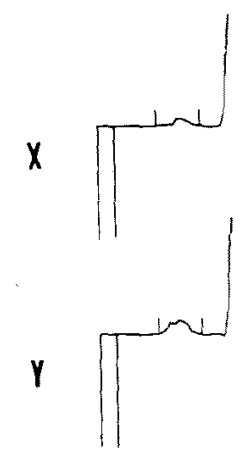

2

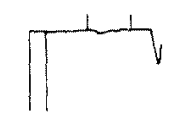

(B)

H

MORMAL MALE

(K.F.41yrs.)
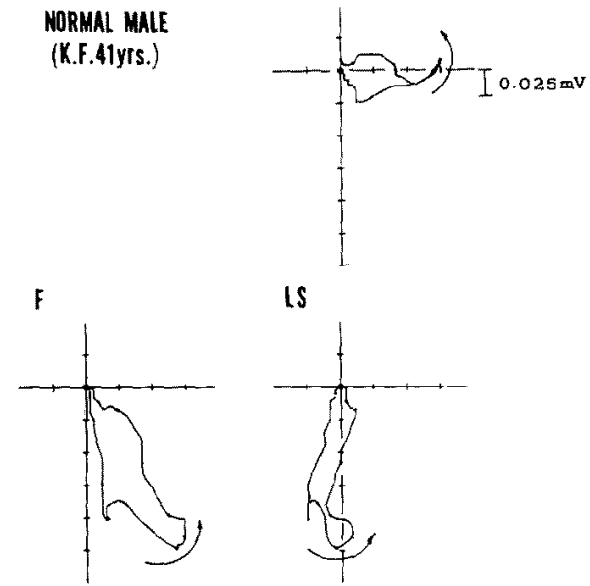

is

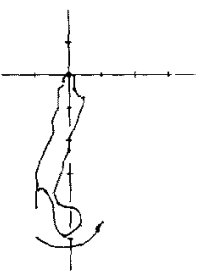

Fig. 4. Planar-projection P loops and orthogonal scalar leads from a normal male.

A short vertical lines drawn on the scalar leads represent the onset and end of the $\mathrm{P}$ wave.

F : frontal plane, $\mathrm{H}$ : horizontal plane, LS: left sagittal plane.

he can correct them through the teletype. The X-Y plotter was also used to display the $\mathrm{P}$ loops in the 3 conventional projection planes (Fig. 4). Computer-measured parameters of $\mathrm{P}$ loops were displayed on the teletype.

The polarities of the $\mathrm{X}, \mathrm{Y}$, and $\mathrm{Z}$ scalar ECGs were designated in accordance with Frank's original description ${ }^{10}$ in which left, inferior and posterior forces were taken as positive.

\section{P duration}

Automated measurements were made of time duration in such manner that in $\mathrm{X}, \mathrm{Y}$, and $\mathrm{Z}$ leads the interval between the beginning of the first oscillation of the $P$ wave and the end of the last registered $P$ wave was defined as spatial time duration.

II. Maximal $\mathrm{P}$ vectors in 3 projection planes

1. Peak time of maximal $P$ vector

Time duration between $\mathrm{P}$ wave onset and points of the maximal $\mathrm{P}$ vectors in 3 projection planes werc measured.

2. Magnitude and direction of maximal $P$ vector

For automated measurements, angles in each of the 3 planes were rotated clockwise from $0^{\circ}$ to $+180^{\circ}$ (to the left) and counter-clockwise to $-180^{\circ}$.

III. Spatial maximal $P$ vector

1. Peak time of spatial maximal $\mathbf{P}$ vector

Automated measurements were made of the time required to arrive at spatial maximal $P$ vector from the onset of the $\mathrm{P}$ wave. 
2. Magnitude, azimuth, and elevation of spatial maximal $P$ vector Spatial maximal $P$ vector is expressed in terms of magnitude (Mag.), azimuth $\left(\mathrm{H}^{\circ}\right)$, and elevation $\left(\mathrm{V}^{\circ}\right)$ on polar coordinate:

$$
\begin{aligned}
& \text { Mag. }=\sqrt{(\mathrm{Px})^{2}+(\mathrm{Py})^{2}+(\mathrm{Pz})^{2}} \\
& \mathrm{H}^{\circ}=-\tan ^{-1}(\mathrm{Pz} / \mathrm{Px}) \\
& \mathrm{V}^{\circ}=\tan ^{-1}\left(\sqrt{(\overline{\mathrm{Px}})^{2}+(\mathrm{Pz})^{2}} / \mathrm{Py}\right)
\end{aligned}
$$

where $\mathrm{Px}, \mathrm{Py}$, and $\mathrm{Pz}_{\mathrm{z}}$ are the areas under the deflections in lead $\mathrm{X}, \mathrm{Y}$, and $\mathrm{Z}$, respectively. Azimuth was set within $\pm 180^{\circ}$ of the $+\mathrm{X}$ axis in the clockwise and counterclockwise direction in accordance with the angle formed by the projection of the spatial maximal $\mathrm{P}$ vector on the horizontal plane and the $+\mathrm{X}$ axis. Automated measurements of elevation were made of the angle formed by the spatial maximal $P$ vector and $+Y$ axis direction. The $+Y$ axis direction was designated as $0^{\circ}$ and the $-\mathrm{Y}$ axis direction as $180^{\circ}$.

IV. Magnitude, azimuth, and elevation of mean polar $\mathrm{P}$ vector ${ }^{12,13 \text { ) }}$

Expressing the digitized value of the $\mathrm{P}$ waves in the scalar $\mathrm{X}, \mathrm{Y}$, and $\mathrm{Z}$ leads by $\mathrm{N}$, the $\mathrm{X}, \mathrm{Y}$, and $\mathrm{Z}$ components of the polar vector $\mathrm{Vx}, \mathrm{Vy}$, and $\mathrm{Vz}$ are given by

$$
\begin{aligned}
& V x=\frac{1}{2} \sum_{i=1}^{N-1}(Y i \cdot Z i+1-Y i+1 \cdot Z i) \\
& V y=\frac{1}{2} \sum_{i=1}^{N-1}(Z i+1 \cdot X i-Z i \cdot X i+1) \\
& V z=\frac{1}{2} \sum_{i=1}^{N-1}(X i+1 \cdot Y i-X i \cdot Y i+1)
\end{aligned}
$$

where subscribed $X-, Y_{-}$, and $Z_{-}$-symbols are the digitized values of the respective lead samples.

Means, standard deviations, and $95 \%$ ranges were calculated by sex and age (20-29, 30-39, 40-49) concerning these parameters of the P loop of the vectorcardiogram. Statistical analysis of the difference in means and distribution between the male and female groups of corresponding ages was conducted to determine any sex differences in each item of measurement. Moreover, similar analyses were made between 2 given groups of 3 male groups to determine any differences by age among male adults. The female sample was examined similarly, as well.

\section{RESULTS}

I. Sex differences

1. P duration (Table II)

No significant difference by sex was observed in any of the age groups.

2. Peak times of maximal $P$ vectors in 3 projection planes (Table III)

The mean of the peak times of the maximal $P$ vectors in the frontal plane of the subjects in their 20's and 40's was prolonged in men, with a 
significant difference $(\mathrm{p}<0.05)$ between the sexes.

3. Magnitudes of maximal $P$ vectors in 3 projection planes (Table IV) The means of the maximal horizontal $P$ vector magnitudes of the subjects in their 20's was $0.056 \mathrm{mV}$ in men and $0.049 \mathrm{mV}$ in women, thus showing

Table II. Means, Standard Deviations, and 95\% Ranges of P Durations

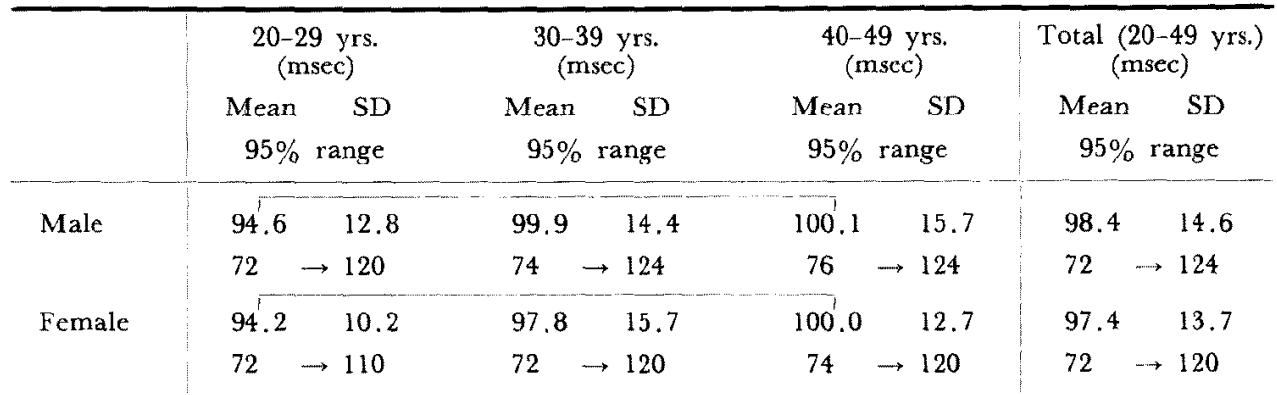

Note: The following symbols are used in Table II-VII.

On the basis of t-test of mean differences, a significant age difference is present between means connected by a fine horizontal line $(p<0.05)$, and by a thick horizontal line $(p<0.01)$.

The symbols $\left({ }^{*} p<0.05\right.$, and $\left.{ }^{* *} p<0.01\right)$ indicate the level of sex differences.

Table III. Means, Standard Deviations, and 95\% Ranges of Frontal, Horizontal, and Left Sagittal Maximal P Vector Peak Times

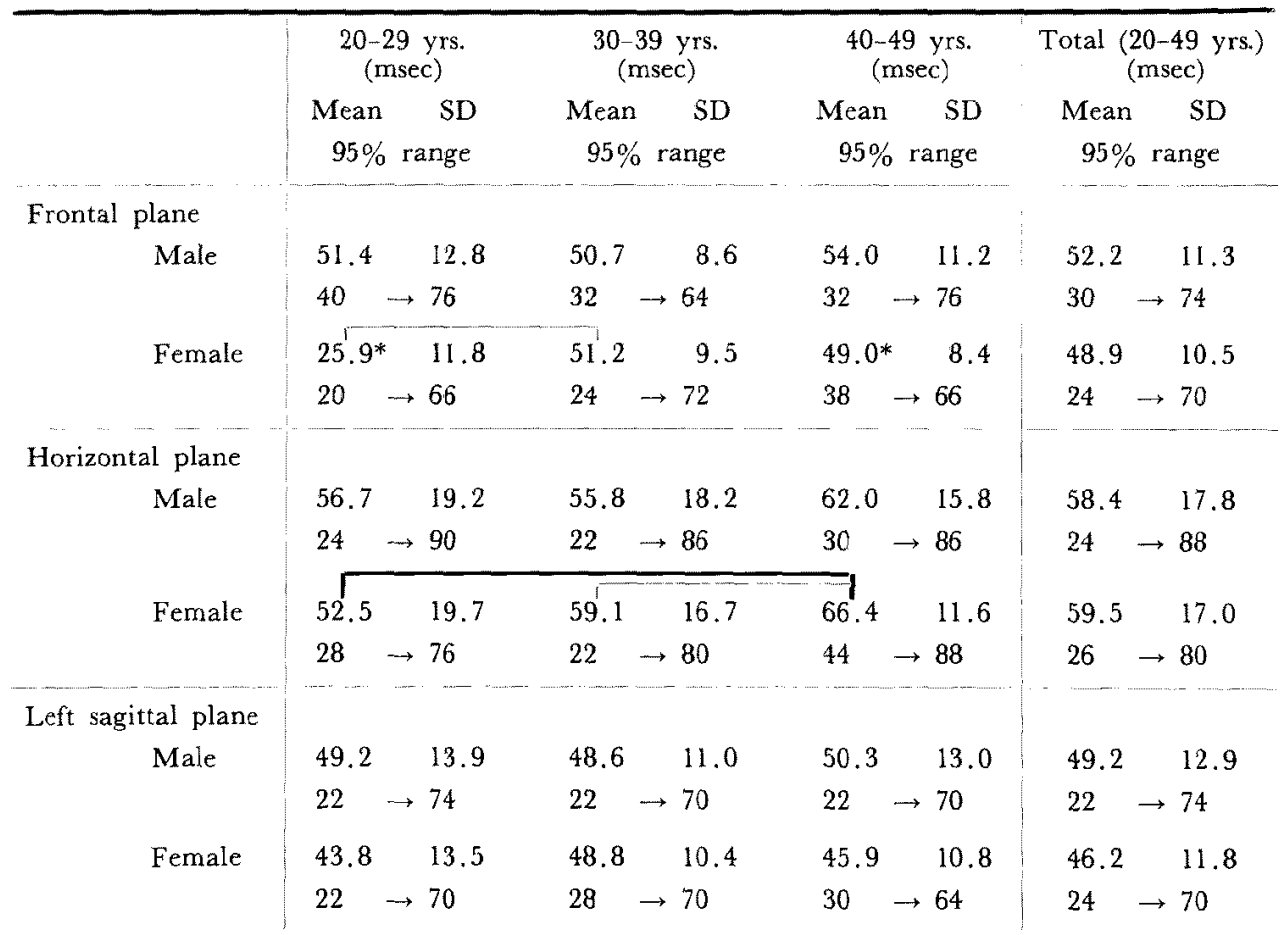

Note: See the note of Table II. 
Table IV. Means, Standard Deviations, and 95\% Ranges of Frontal, Horizontal, and Left Sagittal Maximal P Vector Magnitudes

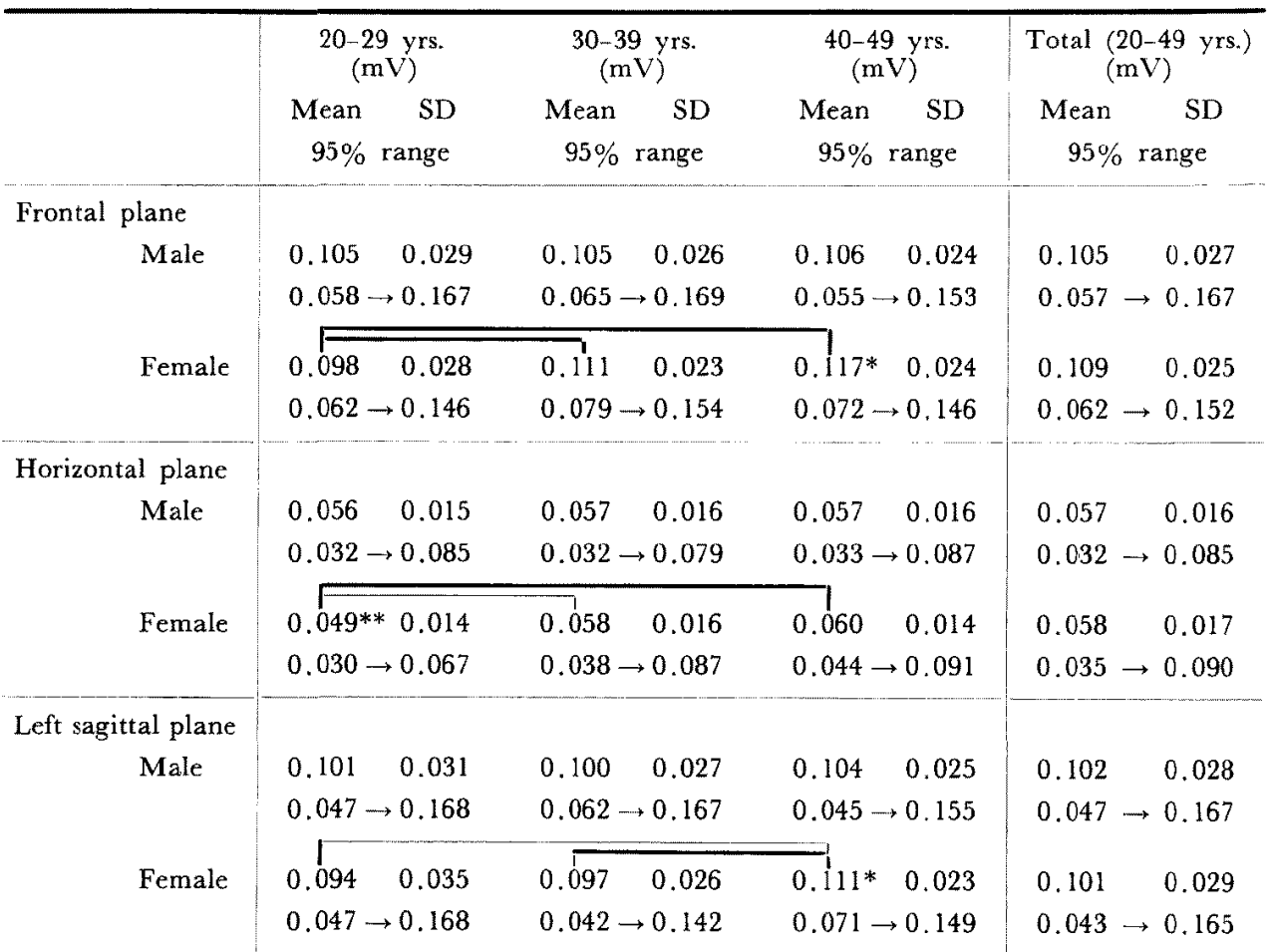

Note: See the note of Table II.

notable difference $(p<0.01)$ by sex (Fig. 5). The mean of the maximal frontal and left sagittal $P$ vector magnitudes of the female subjects in their 40 's had a tendency to exceed those of men in the corresponding age group $(\mathrm{p}<0.05)$.

4. Directions of maximal $\mathrm{P}$ vectors in 3 projection planes

The means of the maximal horizontal $\mathrm{P}$ vector angles of the female subjects in their 30's and $40^{\prime}$ 's was $13.5^{\circ}$ and $-6.3^{\circ}$ respectively, as against $27.1^{\circ}$ and $2.3^{\circ}$ in men. That is, in the groups over 30 years of age, women showed a tendency to shift more posteriorly than men as shown in Fig. 5.

5. Peak time of spatial maximal $\mathrm{P}$ vector (Table VI)

Men in their 40's showed a tendency to take longer peak times than women $(\mathrm{p}<0.05)$.

6. Magnitude of spatial maximal $\mathbf{P}$ vector (Table VI)

The means of females in their 30's and 40's tended to be greater than those of men, and especially those in their 40 's showed a significant difference $(p<0.05)$ by sex. 

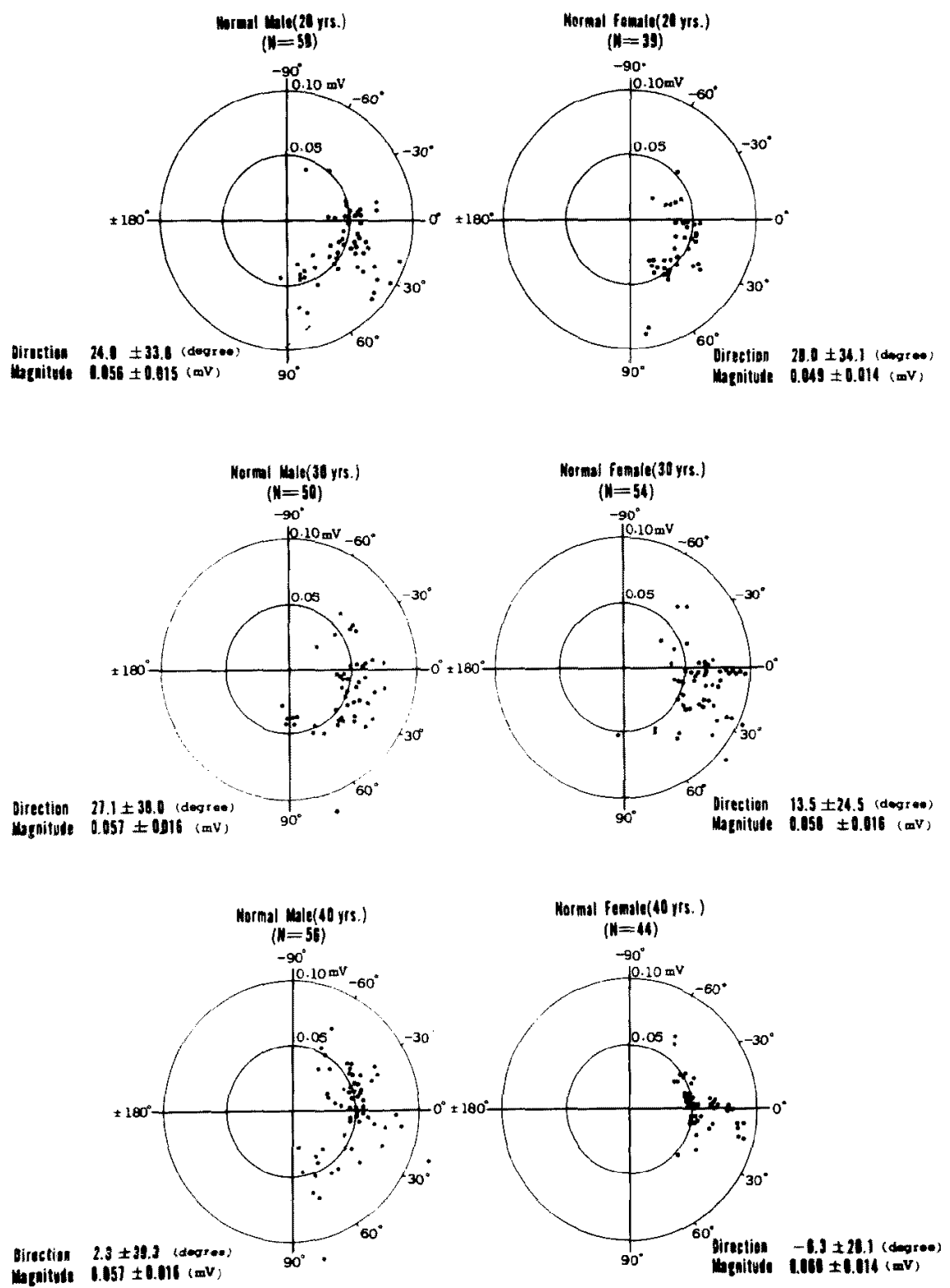

Fig. 5. Distributions of the maximal $P$ vector angles and magnitudes in horizontal plane by sex and age. 
7. Direction of spatial maximal $\mathbf{P}$ vector (Table VI)

As compared with the mean azimuth of 29.3 in men in their 20's, women in the same age bracket recorded 41.4, males showing a tendency to deviate posteriorly $(p<0.05)$. The subjects in their 30's showed a sharp contrast to this, in that men had a mean azimuth of 32.6, while women showed a great posterior displacement with a mean of $13.2(\mathrm{p}<0.01)$.

8. Magnitude of mean polar $\mathrm{P}$ vector (Table VII)

While the male subjects had a tendency toward greater magnitudes in the 20's, the tendency was reversed in the 40's with females registering greater magnitudes, showing a highly significant difference $(p<0.01)$.

9. Direction of mean polar P vector (Table VII)

No significant difference by sex in elevation was observed in any of the age groups. Mean azimuths directed more posteriorly in men than in women in the 20 and 40 year age bracket $(p<0.05)$.

II. Age differences

1. P duration (Table II)

As for this item, both sexes showed a trend toward longer durations with advancing age, creating a significant difference between the groups aged 20-29 and 40-49 ( $\mathrm{p}<0.01)$.

2. Peak times of maximal $P$ vectors in 3 projection planes (Table III)

In females, the mean of the peak times in the horizontal plane showed a tendency to increase with age increments, thus creating a significant difference between those in their 40's and 20's $(p<0.05)$. In males in their 40 's, longer peak times were observed in all of 3 planes.

3. Magnitudes of maximal $P$ vectors in 3 projection planes (Table IV)

In females, the mean of $\mathrm{P}$ vector magnitudes tended to increase with age in all 3 planes. That is, the mean of the frontal maximal $\mathrm{P}$ vector magnitudes of the subjects in their 20's, 30's, and 40's was $0.098 \mathrm{mV}$, $0.111 \mathrm{mV}$, and $0.117 \mathrm{mV}$, respectively, and in the horizontal plane (Fig. 5) the values were $0.049 \mathrm{mV}, 0.058 \mathrm{mV}$, and $0.060 \mathrm{mV}$, respectively, resulting in a significant difference between the 2 groups older and younger than 30 years of age, in the 2 planes. In the left sagittal plane, also, was observed a similar significant difference between the groups older and younger than 40 years of age. But men showed no significant difference with advancing age.

4. Directions of maximal $\mathrm{P}$ vectors in 3 planes (Table $\mathrm{V}$ )

The mean values of horizontal maximal $\mathrm{P}$ vector angles in women in their $20^{\prime} \mathrm{s}, 30^{\prime} \mathrm{s}$, and $40^{\prime} \mathrm{s}$ were $28.0^{\circ}, 13.5^{\circ}$, and $-6.3^{\circ}$, showing a gradual posterior deviation with advancing age. This led to the recognition of a 
Table V. Means, Standard Deviations, and 95\% Ranges of Frontal, Horizontal, and Left Sagittal Maximal P Vector Angles

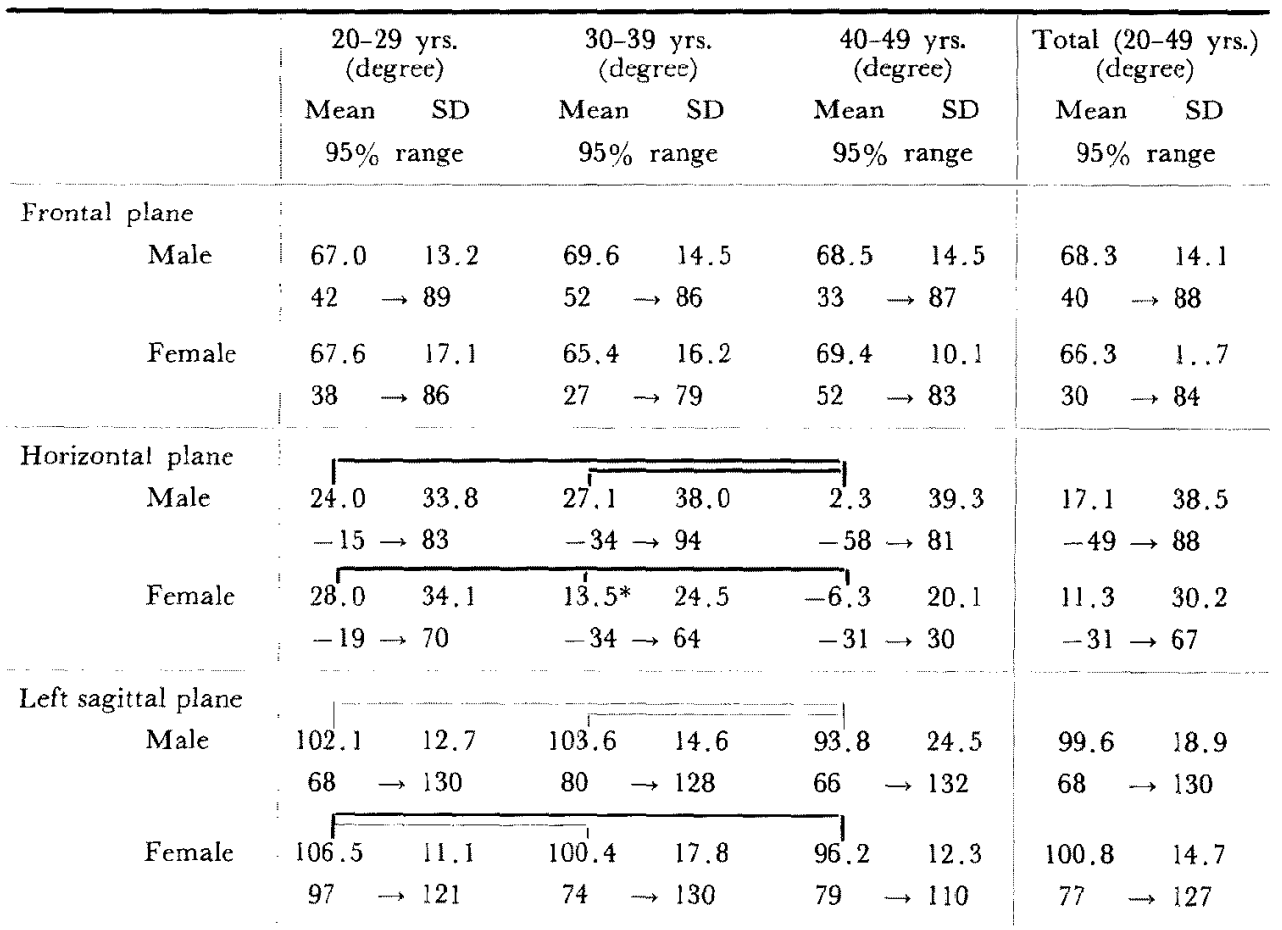

Note: See the note of Table II.

significant difference between any 2 given groups out of the $3 \quad(p<0.01)$ (Fig. 5). As for the mean left sagittal maximal $\mathrm{P}$ vectors, a tendency with advancing age to deviate inferiorly was observed. In men, the mean horizontal maximal P vector angles of the groups aged 20-29 and $30-39$ were 24.0 and 27.1 as against the $2.3^{\circ}$ of those in their $40^{\prime}$ s showing a posterior deviation (Fig. 5). Also, in the left sagittal maximal $P$ vector angles, the group in the 40's showed a tendency to shift inferiorly as compared with the younger groups. No significant difference by sex or age was observed in the direction of the frontal maximal $\mathbf{P}$ vectors.

5. Peak times of spatial maximal $P$ vector (Table VI)

A significant difference was observed in females between those in their 20 's and 30's but not so in other age groups.

6. Magnitudes of spatial maximal $\mathbf{P}$ vector (Table VI)

In females, means showed a tendency toward larger values with advancing age, creating a significant difference between the groups 20-29 and 30 and above. But no significant difference was detected among the 3 male groups. 
Table VI. Means, Standard Deviations, and 95\% Ranges of Spatial Maximal P Vector Peak Times, Magnitudes, and Angles

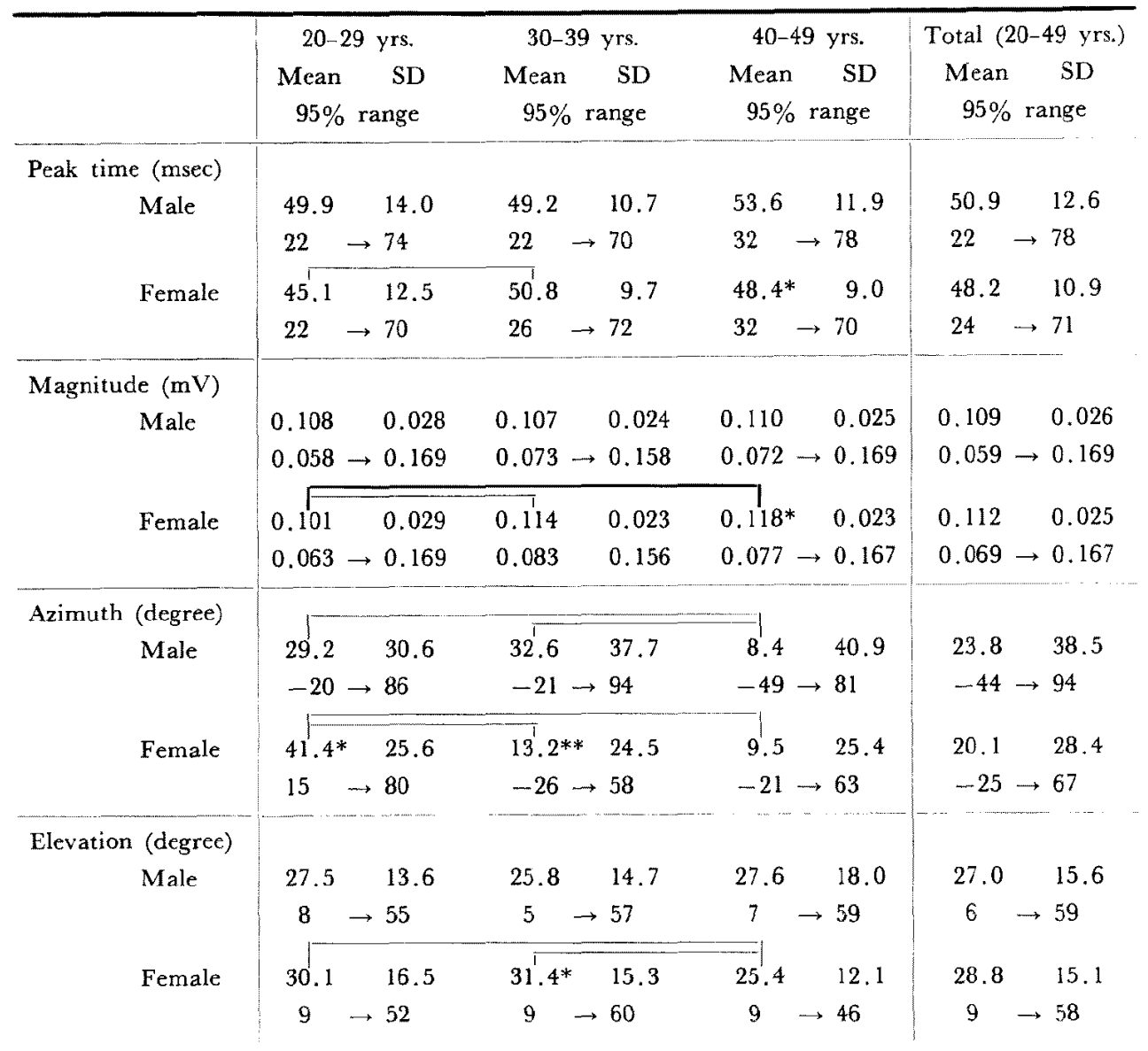

Note: See the note of Table II.

\section{Directions of spatial maximal $\mathbf{P}$ vector (Table VI)}

Mean azimuths of men in their $20^{\prime}$ s and $30^{\prime}$ 's were $29.2^{\circ}$ and $32.6^{\circ}$, while those in their $40^{\prime}$ 's showed a relatively small value $\left(8.4^{\circ}\right)$, registering a considerable posterior deviation. Elevations of the 3 groups showed no significant difference. In females, the mean azimuths of the 3 groups were $41.4^{\circ}, 13.2^{\circ}$, and $9.5^{\circ}$, thus showing a deviation tendency toward the posterior side with age increments. A notable difference by age exists between the groups 20-29 years of age and 30 and above. Also, female elevations were significantly different between the groups older and younger than 40 years of age, the former showing an inferior displacement.

8. Magnitudes of mean polar P vector (Table VII) 
Table VII. Means, Standard Deviation, and 95\% Ranges of Mean Polar P Vector Magnitudes and Angles

\begin{tabular}{|c|c|c|c|c|}
\hline & $20-29$ yrs. & 30-39 yrs. & $40-49$ yrs. & Total (20-49 yrs.) \\
\hline & $\begin{array}{rr}\text { Mean } & \text { SD } \\
95 \% & \text { range }\end{array}$ & $\begin{array}{rr}\text { Mean } & \text { SD } \\
95 \% \text { range }\end{array}$ & $\begin{array}{r}\text { Mean } \\
95 \% \text { range }\end{array}$ & $\begin{array}{r}\text { Mean } \\
95 \% \text { range }\end{array}$ \\
\hline \multicolumn{5}{|c|}{ Magnitude $\left(\mathrm{m} V^{2}\right)$} \\
\hline Male & $\begin{array}{l}0.00300 \quad 0.00172 \\
0.0009 \rightarrow 0.0062\end{array}$ & $\begin{array}{ll}0.00315 & 0.00216 \\
0.0014 \rightarrow 0.0068\end{array}$ & $\begin{array}{ll}0.00337 & 0.00138 \\
0.0011 & \rightarrow 0.0066\end{array}$ & $\begin{array}{l}0.00318 \quad 0.00153 \\
0.0010 \rightarrow 0.0066\end{array}$ \\
\hline Fernale & $\begin{array}{l}0.00224 * 0.00130 \\
0.0007 \rightarrow 0.0045\end{array}$ & $\begin{array}{l}0.00318 \quad 0.00148 \\
0.0010 \rightarrow 0.0062\end{array}$ & $\begin{array}{l}0.00443^{*} 0.00171 \\
0.0022 \rightarrow 0.0067\end{array}$ & $\begin{array}{l}0.00331 \quad 0.00172 \\
0.0010 \rightarrow 0.0062\end{array}$ \\
\hline \multicolumn{5}{|l|}{ Azimuth (degree) } \\
\hline Male & $\begin{array}{l}30.0 \quad 17.2 \\
-95 \rightarrow 110\end{array}$ & $\begin{array}{ll}53.2 & 21.6 \\
14 \rightarrow 97\end{array}$ & $\begin{array}{l}37.6 \\
-17 \rightarrow 69\end{array}$ & $\begin{array}{l}41.4 \rightarrow 33.0 \\
-36 \rightarrow 99\end{array}$ \\
\hline Female & $\begin{array}{l}52.8 * 26.7 \\
-17 \rightarrow 88\end{array}$ & $\begin{array}{ll}43.7 & 42.1 \\
-71 \rightarrow 112\end{array}$ & $\begin{array}{l}49.3 * 16.3 \\
-24 \rightarrow 82\end{array}$ & $\begin{array}{l}48.1 \rightarrow 31.5 \\
-35 \rightarrow 92\end{array}$ \\
\hline \multicolumn{5}{|l|}{ Elevation (degree) } \\
\hline Male & 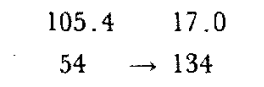 & 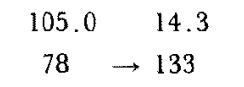 & 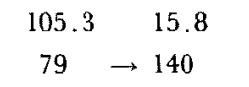 & 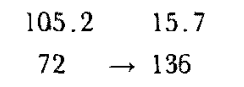 \\
\hline Female & 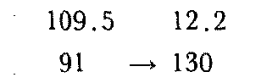 & 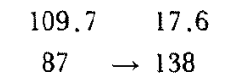 & 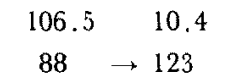 & 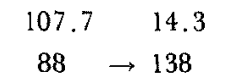 \\
\hline
\end{tabular}

Note: See the note of Table II.

The mean values of the 3 female groups in ascending age order were $0.00224 \mathrm{mV}^{2}, 0.00318 \mathrm{mV}^{2}$, and $0.00443 \mathrm{mV}^{2}$, showing a highly significant difference between any given pair out of these 3 groups. Men also showed a tendency toward greater values with age, but not sufficient to establish significant difference by age.

9. Directions of mean polar $\mathbf{P}$ vector (Table VII)

Although the mean azimuths of the male subjects in their 30's were significantly more posterior than those of the other 2 age groups, the 3 groups showed almost negligible difference in elevation. Females showed no significant difference in either azimuth or elevation.

\section{Discussion}

Very few, if any, reports have been made on sex and/or age differences of the P loop in the Frank lead VGG in Japan, ${ }^{1}$ ' Europe, and America. ${ }^{4}$ ' This is partly because major interest in VGG research has been focussed on the variations of such ventricular complexes as QRS and T loops, and partly because of the technical difficulties involved. P loop signals, with a generally 
far lower voltage than QRS and T loops, require large amplification for detailed analyses. While the amplification of the wave form itself has been made relatively easy lately, the problem still remains in eliminating the noise from electromyograms and lead cables which is simultaneously amplified. Installing analog or digital filters, ${ }^{14)}$ in limited numbers, may suggest a way out of the problem, but it cannot be denied that the filters somewhat distort the original wave form. With the recent advances in computer technology, it has become common practice to employ the averaging, or summation technique ${ }^{15)}$ which makes possible the detection of small signals even in the presence of interference from undesirable noise. ${ }^{16)-19}$ ) Brody et al ${ }^{18)}$ and Selvester et $\mathrm{al}^{19}$ ' have reported that they used this technique to eliminate the noise in $\mathrm{P}$ waves and loops to successfully observe $\mathrm{P}$ waves composed of comparatively high frequency components such as notches ${ }^{20)}$ on $\mathrm{P}$ loops. In the present study, a $\mathrm{P}$ wave area was summed-up over 8 consecutive beats by a small digital computer to eliminate noise, which enabled us to obtain loops with a satisfactory $\mathrm{S} / \mathrm{N}$ ratio and to observe notches. ${ }^{6 /-9)}$

The followings are the physiological factors ${ }^{21,22)}$ generally considered as affecting the $\mathrm{P}$ vector. First and foremost are the effects of respiration. Deep inspiration veers the $P$ vector rightward and inferiorly and increases it, while deep expiration results in the decrease of the $\mathrm{P}$ vector. Next comes the influence of the autonomic nervous system. While the $\mathrm{P}$ vector increases when the sympathetic nerves are tense, it decreases when the parasympathetic nerves are tense. Thirdly comes the influence of exercise. ${ }^{22}$ Increased beat output induced by exercise adds to ventricular work and throws tense the sympathetic nerves, resulting in the increase of the $\mathrm{P}$ vector. Other factors involved are the anatomical locations of the heart, diaphragm, etc. Therefore, it becomes imperative that all these physiological variables should be minimized to make a detailed analysis of normal values and ranges.

In the present study, the subject was placed in the supine position at rest with normal breathing for all measurements. Moreover, those with tachycardia of over $90 / \mathrm{min}$ and bradycardia of lower than $60 / \mathrm{min}$ were eliminated beforchand. With the adoption of a statistical method we have tried to determine sex and agc differences about each item of measurement, in which allowance was made for beat to bcat variation ${ }^{23)}$ (Fig. 6) within at least a cycle of respiration by summing a $\mathrm{P}$ wave area over 8 consecutive beats.

\section{Sex differences}

Von der Groeben et al ${ }^{41}$ reported earlier that in analyzing the spatial $\mathrm{P}$ vectors aged 20-59, they found no essential differences between the 2 sexes. We also failed to find any item in which significant sex-related differences ex- 


\section{Beat to Beat Variation of Frontal P Loops}

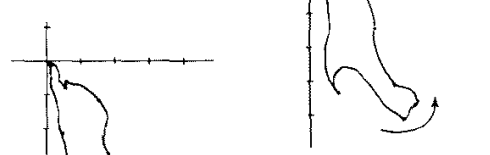

(1)

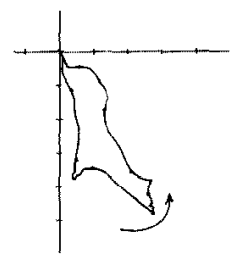

(4)

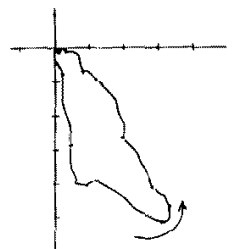

(2)

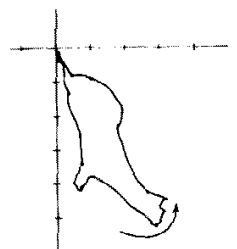

(5)

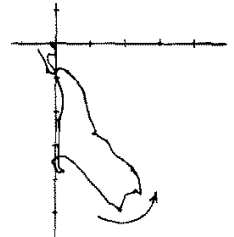

(3)

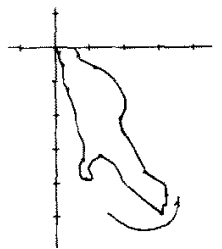

(6)

Fig. 6. Beat-to-beat variations in the frontal $P$ loop.

The $P$ loop labelled "averaged" indicates the resultant $P$ loop obtained with the averaging technique from 8 successive beats, and those numbered (1) to (6) the individual $P$ loops.

isted in analyzing sex differences among all the males and females with all the age groups (20-49) put together. But, in analyzing the data obtained concerning the 17 items measured on the male and female subjects, both subsumed into the 3 age groups of 20-29, 30-39, and 40-49, we have found differences in 5 items in the first age bracket, 3 in the second, and 7 in the third. These results suggest that different diagnostic criteria will be needed for men and women.

It is to be noted here that confirmation has already been made in and outside Japan of the obvious sex differences in the QRS and T loops in Frank's system. Sotobata et al $^{24)}$ recognized significant sex differences in 43 items of measurement out of 64 . Also, Ishikawa ${ }^{25)}$ has reported that he observed sex differences in 40 items out of 44 . Thus, it is noteworthy that the foregoing data suggest that the $P$ loop is less influenced by sex than $Q R S$ and T loops.

\section{Age differences}

Although it is considered best to conduct a longitudinal follow-up study on the same subject groups for a sufficiently long period of time in order to determine the effects of aging on electrocardiographic wave forms, because of the difficulties involved in a long-term observation, most of the conventional studies have been cross-sectional in that the results from young subjects were contrasted with those from aged ones. 
Hori ${ }^{11}$ studied the $\mathrm{P}$ loops by Frank's system of a young group aged 1736 , and a middle-aged and aged group, aged 40-70, and found the effects of aging on 7 parameters out of 11 , all of which are included in the authors' measurements. He reported that the middle-aged and aged group, as compared with the young group, had greater horizontal and spatial maximal $\mathrm{P}$ vectors, which were displaced more posteriorly.

The authors have examined 3 age groups of 20's, 30's, and 40's for possible age difference of both sexes, by age between the sexes. In men, the effects of aging were observed in 5 parameters measured out of 17 and in that time, durations extended and maximal vectors were displaced posteriorly. Of the 5 items in which age difference was recognized, 4 items showed a significant difference between the groups older and younger than 40 years of age. Considering the fact that all of the subjects in the aforementioned study by Hori ${ }^{11}$ were males, our data strongly support the suggestion that the age 40 be designated as a critical one in preparing standards for normal values of the $\mathrm{P}$ loop in the Frank lead system. In females, changes with advancing age observed in 13 items out of 17 , thus leaving only 4 parameters including frontal maximal $P$ vectors and direction of mean polar $P$ vectors unaffected. Of the 13 items in which change with age was observed, 2 showed a significant difference between given pairs of the 3 age groups, 5 items suggested that the age 30 be designated as critical, and 5 items the agc 40 . These findings suggest that the above data be taken into consideration in preparing age standards.

In conclusion, the over-all results the author et al have obtained suggest that sex and age-wise diagnostic standards should be established in conducting proper VCG diagnosis of the P loop.

\section{REFERENCES}

1. Hori K: A quantitative study on normal P-SE loop of vectorcardiogram and $\mathbf{P}$ wave of scalar electrocardiogram by Frank lead system. Jap Circulat J 31 : 1347, 1967

2. Forkner GE, Hugenholtz PG, Levine HD: The vectorcardiogram in normal young adults, Frank lead system. Am Heart J 62: 237, 1961

3. Draper HW, Poffer CJ, Stallmann FW, Littmann D, Pipberger HV: The corrected orthogonal electrocardiogram and vectorcardiogram in 510 normal men (Frank lead system). Circulation 30: 853, 1964

4. von der Groeben J, Fisher DD, Toole JG: Temporospatial frequency distribution of $\mathbf{P}$, QRS, and $\mathrm{T}$ in normal man and woman. Am Heart J 75: 487, 1968

5. Ishikawa K, Kini PM, Pipberger HV: P wave analysis in 2464 orthogonal electrocardiograms from normal subjects and patients with atrial overload. Circulation 58: 565, 1973

6. Yokota M, Yamauchi K, Tanimura H, Watanabe Y, Sotobata I, Yasui S: Normal P loops analysis with computer-averaging technique. Jap J Med Electr Biol Engin 11 (Suppl): 79, 1973 (in Japanese)

7. Yokota M, Yamauchi K, Tanimura H, Miyagi Y, Futamura $Y$, Ichie $Y$, Takeuchi S, Watanabe $Y$, Sotobata I, Yasui $S$ : Computer analysis of $P$ loops with averaging technique, normal 
and mitral valvular disease. Jap Circulat J 38: 625, 1974

8. Yokota M, Yamauchi K, Tanimura H, Watanabe $\mathrm{Y}$, Sotobata $I_{\text {, }}$ Yasui S: A quantitative study on normal $\mathrm{P}$ loops of the Frank vectorcardiogram, sex and age differences. Heart 7: 315, 1975 (in Japanese)

9. Yokota M, Watanabe Y, Sotobata I, Yasui S: Computer analysis of normal and abnormal P loops of the Frank vectorcardiogram. Adv Cardiol 16: 227, 1976

10. Frank E: An accurate, clinically practical system for spatial vectorcardiography. Circulation 13: 737, 1956

11. Watanabe $\mathrm{Y}$, Yokoi M, Yasui S, Okamoto N: Automated system for electrocardiographic diagnosis. Biotech 2: 186, 1971 (in Japanese)

12. Burger HC, Vaane JP: A criterion characterizing the orientation of a vectorcardiogram in space. Am Heart J 56: 29, 1958

13. Okamoto $\mathrm{N}$, Simonson $\mathrm{E}$ : Separation of normal and abnormal vectorcardiograms. Am $\mathrm{J}$ Cardiol 18: 682,1966

14. Stallmann FW, Pipberger HV: Automatic recognition of electrocardiographic waves by digital computer. Circulat Res 9: 1138, 1961

15. Dawson GD: A summation technique for the detection of small evoked potentials. EEG Clin Neurophysiol 6: 65, 1954

16. Hon EH, Lee ST: Noise reduction in fetal electrocardiography. Am J Obst \& Gynec 87: 1086,1963

17. Irisawa $\mathrm{H}$, Seyama $\mathrm{I}$ : The configuration of the $\mathbf{P}$ wave during mild exercise. Am Heart J 71 : 467,1966

18. Brody DA, Arzbaecher RC, Woolsey MD, Sato $T$ : The normal atrial electrocardiogram, Morphologic and quantitative variability in bipolar extremity leads. Am Heart J 74: 4, 1967

19. Selvester RH, Pearson RB: High-gain averaged atrial vectorcardiograms. Proc 11 th International Symposium on Vectorcardiography, 1970

20. Irisawa $H$, Morio $M$, Seyama $I$ : The presence of notches on the normal $P$ wave. Jap $J$ Physiol 15: 17, 1965

21. Abildskov JA, Syracuse NY: The atrial complex of the electrocardiogram. Am Heart J 57: 930,1959

22. Zimmerman HA, Bersano E, Dicosky C: The auricular electrocardiogram. Charles C Thomas, Springfield, lllinois, p 31, 1968

23. Brody DA, Woolsey MD, Arzbaecher RC: Application of computer techniques to the detection and analysis of spontaneous $P$ wave variations. Circulation 36:359, 1967

24. Sotobata I, Richman H, Simonson E: Sex differences in the vectorcardiogram. Circulation 37: 438, 1968

25. Ishikawa $\mathrm{H}$ : Sex and age differences in the Frank vectorcardiograms of normal Japanese adults. Jap Circulat J 37: 543, 1973 